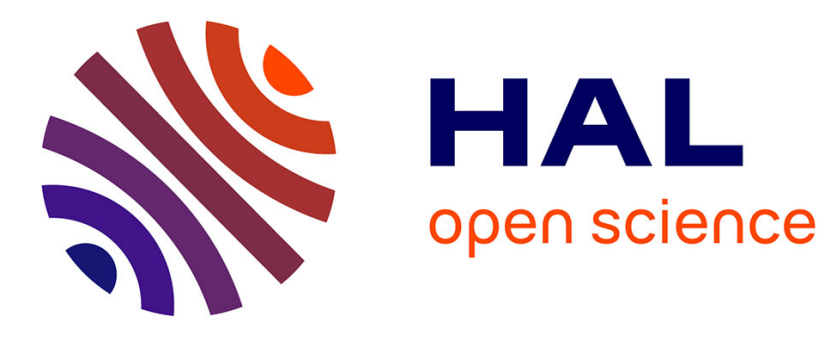

\title{
1100delC and male breast cancer in the Netherlands
}

\author{
Marijke Wasielewski, Michael A. Bakker, Ans Ouweland, Marion E. \\ Meijer-van Gelder, Henk Portengen, Jan G. M. Klijn, Hanne Meijers-Heijboer, \\ John A. Foekens, Mieke Schutte
}

\section{- To cite this version:}

Marijke Wasielewski, Michael A. Bakker, Ans Ouweland, Marion E. Meijer-van Gelder, Henk Portengen, et al.. 1100delC and male breast cancer in the Netherlands. Breast Cancer Research and Treatment, 2008, 116 (2), pp.397-400. 10.1007/s10549-008-0162-7 . hal-00478498

\section{HAL Id: hal-00478498 \\ https://hal.science/hal-00478498}

Submitted on 30 Apr 2010

HAL is a multi-disciplinary open access archive for the deposit and dissemination of scientific research documents, whether they are published or not. The documents may come from teaching and research institutions in France or abroad, or from public or private research centers.
L'archive ouverte pluridisciplinaire HAL, est destinée au dépôt et à la diffusion de documents scientifiques de niveau recherche, publiés ou non, émanant des établissements d'enseignement et de recherche français ou étrangers, des laboratoires publics ou privés. 


\title{
CHEK2 1100delC and male breast cancer in the Netherlands
}

\author{
Marijke Wasielewski · Michael A. den Bakker · Ans van den Ouweland · \\ Marion E. Meijer-van Gelder · Henk Portengen · Jan G. M. Klijn · \\ Hanne Meijers-Heijboer · John A. Foekens $\cdot$ Mieke Schutte
}

Received: 11 August 2008/Accepted: 11 August 2008/Published online: 31 August 2008

(C) Springer Science+Business Media, LLC. 2008

\begin{abstract}
Mutations in the breast cancer susceptibility genes $B R C A 1, B R C A 2$, and $C H E K 2$ are known risk factors for female breast cancer. Mutations in BRCA1 and BRCA2 also are associated with male breast cancer (MBC). Similarly, it had been suggested in the original CHEK2 identification report that the CHEK2 1100delC mutation confers an increased risk for MBC. Here, we have evaluated the risk of $C H E K 21100 \mathrm{delC}$ for MBC by genotyping CHEK2 1100delC in 23 familial and 71 unselected Dutch MBC cases. None of the 23 familial MBC cases carried the CHEK2 1100delC mutation. In contrast, CHEK2 1100delC was present in 3 of the $71(4.2 \%)$ unselected MBC cases, which was significantly more prevalent than the $1.1 \%$ Dutch population frequency assessed in 1,692 individuals $(P=0.05$, OR $=4.1,95 \%$ CI 1.2-14.3). Our data suggest
\end{abstract}

M. Wasielewski · M. E. Meijer-van Gelder · H. Portengen · J. G. M. Klijn · H. Meijers-Heijboer · J. A. Foekens ·

M. Schutte $(\square)$

Department of Medical Oncology, Josephine Nefkens Institute, Erasmus University Medical Center, PO Box 2040, 3000 CA, Rotterdam, The Netherlands

e-mail: a.schutte@erasmusmc.nl

M. A. den Bakker

Department of Pathology, Josephine Nefkens Institute, Erasmus University Medical Center, Rotterdam, The Netherlands

A. van den Ouweland · H. Meijers-Heijboer

Department of Clinical Genetics, Erasmus University Medical Center, Rotterdam, The Netherlands

J. A. Foekens

Department of Cancer Genomics Centre, Erasmus University

Medical Center, Rotterdam, The Netherlands that, in the Netherlands, CHEK2 1100delC is associated with an increased risk for MBC.

Keywords Cancer susceptibility - CHEK2 - CHK2 Male breast cancer

\section{Introduction}

Male breast cancer (MBC) is a rare disease that accounts for less than $1 \%$ of all breast cancers. Major risk factors for MBC are Klinefelter syndrome, disorders associated with high estrogen levels, testicular disorders, and a family history of breast cancer. Germ line mutations in the breast cancer susceptibility genes $B R C A 2$ and $B R C A 1$ account for approximately $4-14 \%$ of familial MBC cases, with higher frequencies found in $B R C A 2$ founder populations [1]. Apart from $B R C A 2$ and $B R C A 1$ mutations, mutations in the androgen receptor, the CYP17 and the PTEN genes have also been implicated in MBC [1-3]. Yet, it is still unclear what the underlying predisposition in the majority of $\mathrm{MBC}$ cases is.

In 2002, we and others identified the CHEK2 1100delC mutation as a breast cancer susceptibility allele $[4,5]$. We estimated that female CHEK2 1100delC carriers had a twofold increased breast cancer risk compared with noncarriers, classifying the mutation as a moderate-risk breast cancer susceptibility allele [6]. In addition to a female breast cancer risk, 4 of 33 (12\%) index cases of families with at least one MBC case were CHEK2 1100delC positive suggesting that the mutation also might confer a risk for MBC [4]. Thus far, the prevalence of CHEK2 1100delC in $\mathrm{MBC}$ has been evaluated in 12 additional studies [7-18]. Yet, only 3 of 627 genotyped samples carried the CHEK2 1100delC mutation, raising doubts on the association of 
CHEK2 1100delC with MBC. Evaluation of CHEK2 1100 delC in $\mathrm{MBC}$ is however severely hampered by the moderate cancer risks associated with CHEK2 1100delC, the large differences in $C H E K 2$ 1100delC population frequencies and the rarity of the MBC phenotype.

In the Netherlands, the relatively high CHEK2 1100delC population frequency of $1.1 \%$ previously had allowed the identification of CHEK2 $1100 \mathrm{delC}$ as a breast cancer allele and a colorectal cancer allele [4, 19, 20]. Here, we have exploited our unique opportunity to assess CHEK2 1100delC-associated cancer risks by screening CHEK2 1100delC in 94 Dutch MBC cases.

\section{Materials and methods}

Male breast cancer cases and controls

The evaluated MBC cohort consisted of 23 familial and 71 unselected $\mathrm{MBC}$ cases, together including all available MBC cases registered at Erasmus MC. All familial breast cancer cases were ascertained through the Rotterdam Family Cancer Clinic at Erasmus MC (Table 1). A family history of MBC was defined by the presence of at least two breast cancer cases in first- or second-degree relatives of whom at least one was a man (21 families) or by the presence of at least one MBC case who had two or more first-degree relatives diagnosed with cancer types other than breast carcinoma (2 families). Screening of all $23 \mathrm{MBC}$ families had identified BRCA2 and BRCA1 germ line mutations in five and three families, respectively. The CHEK2 1100delC mutation was tested in blood-derived DNA of $14 \mathrm{MBC}$ cases and in 17 first-degree relatives of $9 \mathrm{MBC}$ cases of whom no DNA was available (Table 1). Unselected MBC cases included all available MBC cases from the Erasmus MC Pathology archive (16 paraffin-embedded tumors), the Rotterdam Family Cancer Clinic (3 blood-derived DNA

Table 1 Inclusion criteria of familial MBC cases

\begin{tabular}{llll}
\hline Inclusion criteria MBC families & \multicolumn{3}{l}{ Mutation status } \\
\cline { 2 - 4 } & Non-BRCA1/2 & BRCA1 & BRCA2 \\
\hline$\geq 1$ MBC with $\geq 1$ FBC 1st/2nd & 9 & 1 & 2 \\
$\quad$ DGR (MBC tested) & & 2 & 3 \\
$\geq 1$ MBC with $\geq 1$ FBC 1st/2nd & 4 & - & - \\
$\quad \begin{array}{l}\text { DGR (BRC in 1st DGR tested) } \\
1 \text { MBC with } \geq 2 \text { non-BRC 1st } \\
\quad \text { DRG (MBC tested) } \\
\text { Total (23) }\end{array}$ & 2 & 3 & 5 \\
\hline
\end{tabular}

FBC, female breast cancer; MBC, male breast cancer; non-BRC, cancer types other than breast carcinoma; 1st/2nd DGRs, first- or second-degree relatives samples), and the Rotterdam Medical Oncology Tumor Bank (52 fresh-frozen tumors). None of the unselected MBC cases had been screened for $B R C A 1$ or $B R C A 2$ mutations. Of note, 25 fresh-frozen MBC tumors had also been part of a previous study that had evaluated the clinical relevance of steroid hormones and factors involved in the urokinase system among male and female breast cancers [21]. The Medical Ethical Review Board at Erasmus MC has approved the study, which was carried out according to the Code of Conduct of the Federation of Medical Scientific Societies in the Netherlands (http://www.fmwv.nl/).

Population controls were previously reported and included a hospital-based cohort of 967 spouses of heterozygous cystic fibrosis mutation carriers registered by the department of Clinical Genetics at Erasmus MC, a population-based cohort of 460 persons without cancer after age 55 years from the Erasmus Rotterdam Health and the Elderly Study (ERGO) and a cohort of 265 randomly selected blood donors [6, 22].

\section{CHEK2 1100delC genotyping}

CHEK2 1100delC genotyping was performed on DNA by allele-specific oligonucleotide hybridization, with confirmation of mutant cases by long-range PCR and sequencing of an independent template, as described [4].

\section{Statistics}

The difference between CHEK2 1100delC frequency in cancer cases and controls among $C H E K 21100 d e l C$ carriers versus non-carriers was tested by using Fisher's Exact Test. Odds ratios (OR) and corresponding 95\% confidence intervals $(95 \% \mathrm{CI})$ were calculated using Woolf's method. All statistical analyses were performed with STATA statistical package, release 10 (STATA Corp, College Station, TX).

\section{Results and discussion}

Genotyping of CHEK2 1100delC identified 3 of $94 \mathrm{MBC}$ cases $(3.2 \%)$ as heterozygous carriers of the CHEK2 1100delC mutation (Table 2). All three CHEK2 1100delC cases were identified among the 71 unselected MBC cases (4.2\%, Table 2), which was significantly more prevalent compared with the $1.1 \%$ Dutch population frequency $(P=0.05$, OR $=4.1,95 \%$ CI $1.2-14.3)$. Our results thus suggest that CHEK2 1100delC is associated with an increased risk for $\mathrm{MBC}$ in the Dutch population.

Age at diagnosis and cytosolic estrogen receptor (ER) and progesterone receptor $(\mathrm{PgR})$ levels were available for 50 unselected MBC cases including all three CHEK2 1100delC 
Table 2 Summary of reported CHEK2 1100delC genetic screens in male breast cancer cases

\begin{tabular}{llllll}
\hline Reference & Population & \multicolumn{2}{l}{ CHEK2 1100delC+/total tested (\%) } & \\
\cline { 3 - 5 } & & Population controls & Unselected MBC cases & Familial MBC cases & All MBC cases \\
\hline Present study & NL & $\mathbf{1 8 / 1 , 6 9 2}(\mathbf{1 . 1})$ & $\mathbf{3 / 7 1}(\mathbf{4 . 2})$ & $\mathbf{0 / 2 3}$ & $\mathbf{3 / 9 4}(\mathbf{3 . 2})$ \\
{$[4]$} & UK/NL/US/Germany & $18 / 1,620(1.1)$ & & $4 / 33(12.1)$ & $4 / 33(12.1)$ \\
{$[13,18]$} & Finland & $26 / 1,885(1.4)$ & $2 / 132(1.5)$ & $0 / 18$ & $2 / 150(1.3)$ \\
{$[9,14,17]$} & UK & $20 / 3,749(0.5)$ & $0 / 79$ & $1 / 90(1.1)$ & $1 / 169(0.6)$ \\
{$[11,14,15]$} & USA & $8 / 2,261(0.4)$ & $0 / 109$ & $0 / 19$ & $0 / 128$ \\
{$[16]$} & Israel & $0 / 146$ & $0 / 31$ & $0 / 23$ & $0 / 54$ \\
{$[10]$} & Italy & $0 / 263$ & $0 / 77$ & $0 / 25$ & $0 / 102$ \\
{$[8]$} & Germany & $6 / 1,315(0.5)$ & & $0 / 12$ & $0 / 12$ \\
{$[12]$} & Australia & $1 / 736(0.1)^{\mathrm{a}}$ & & $0 / 7$ & $0 / 7$ \\
{$[7]$} & South Korea & n.a. & & $0 / 5$ & $0 / 5$ \\
& Total & & $5 / 499$ & $5 / 255$ & $10 / 754$ \\
\hline
\end{tabular}

The summary includes data from the present study and 13 studies that have thus far screened CHEK2 1100delC in MBC cases

NL, the Netherlands; UK, United Kingdom; USA, United States of America; MBC, male breast cancer

${ }^{\text {a }}$ Controls were obtained from Ref. [6]

n.a., not available

Bold data indicate our data in the present study

MBC cases. The CHEK2 $1100 \mathrm{delC}$ MBC cases were diagnosed with breast cancer at age 64, 66, and 73 years, which was not different from the average age at diagnosis of 67 years among 47 CHEK2 1100 delC negative MBC cases. All three $C H E K 2$ 1100delC cases were ER positive as were 41 of 47 (87\%) CHEK2 1100delC negative cases. Similar, two of the three CHEK2 1100delC MBC cases (67\%) were PgR positive compared to 37 of 47 (78\%) CHEK2 1100delC negative cases. Clinical follow-up including tumor stage, lymph node involvement, local and/or distant metastasis data were available for two CHEK2 1100delC and 33 CHEK2 1100delC negative unselected MBC cases. Overall, the median follow-up time of $\mathrm{MBC}$ cases still alive was 47 months (range 2-165 months). The first CHEK2 $1100 \mathrm{delC}$ case was diagnosed with a lymph node-negative T1 breast tumor and the second case had a lymph node-positive T4 breast tumor. Both cases died of bone metastasis, 24 and 36 months after their diagnosis, respectively. In contrast, distant metastasis at diagnosis and during follow-up was reported in 12 of 33 (36\%) CHEK2 1100delC negative MBC cases and only two of these had a sole relapse to the bone. In agreement with previous reports on bone metastatic disease and ER status, all four MBC cases diagnosed with bone metastasis were ER positive, affirming the strong association between relapse to bone and positive ER status [23, 24].

In the initial CHEK2 1100delC identification report, 4 unrelated $C H E K 21100 \mathrm{del} C$ cases had been identified among 33 (12\%) high-risk BRCA1/BRCA2 negative MBC families, suggesting an estimated 10-fold increased MBC risk for CHEK2 1100delC MBC carriers [4]. Yet, here we did not identify CHEK2 $1100 \mathrm{delC}$ among the 23 familial MBC cases analyzed. The analyzed familial MBC cohort included eight confirmed BRCA1/BRCA2 positive MBC cases (Table 1). These cases were a priori unlikely to carry $C H E K 21100 \mathrm{delC}$ as the $C H E K 21100 \mathrm{delC}$ mutation is quite uncommon among $B R C A 1 / B R C A 2$ mutation carriers $[4,6]$. Additionally, four $B R C A 1 / B R C A 2$ negative families had been included for which the MBC case was not available for CHEK2 1100delC genotyping (Table 1). As a whole, we thus had 11 BRCA1/ BRCA2 negative familial MBC cases available for CHEK2 1100delC analysis, a too low number to establish a possible correlation between CHEK2 1100delC and familial BRCA1/ $B R C A 2$ negative breast cancer.

In addition to our previous 4 of $33 \mathrm{MBC}$ cases [4], thus far, only three CHEK2 $1100 \mathrm{delC}$ cases have been identified worldwide among the additional $627 \mathrm{MBC}$ cases genotyped (Table 2) [7-18]. In contrast to the initial CHEK2 1100delC identification report [4] and our current report, this low frequency of $0.5 \%$ ( 3 of $627 \mathrm{MBC}$ cases) had suggested that CHEK2 1100delC is not a risk allele for MBC. However, most of the reported studies had low CHEK2 1100delC population frequencies and also had used small MBC cohorts [4, 7-18], resulting in a lack of statistical power to detect $C H E K 2$ 1100delC-associated cancer risks. Interestingly, the Finnish CHEK2 1100delC MBC study had comparable power to our study, but failed to identify a CHEK2 1100delC related MBC risk [13, 18]. Similarly, we previously had identified CHEK2 $1100 \mathrm{delC}$ as a risk allele for Dutch colorectal cancer cases whereas no such risk could be detected for Finnish colorectal cancer cases [20, 25]. These observations might suggest the presence of additional susceptibility alleles in the Dutch population that are absent 
in the Finnish population. One might speculate that the same putative Dutch cancer susceptibility allele acts in synergy with $C H E K 21100$ delC to confer a higher risk for colorectal cancer as well as male breast cancer. Or, are there two or more cancer susceptibility alleles present in the Dutch population that, together with CHEK2 1100delC, are responsible for the Dutch CHEK2 1100delC phenotype of female breast cancer, male breast cancer, and colorectal cancer?

Acknowledgments Funding was provided by the Dutch Cancer Society, grant DDHK 2003-2862, and the Netherlands Genomics Initiative (NGI)/Netherlands Organization for Scientific Research (NOW).

\section{References}

1. Weiss JR, Moysich KB, Swede H (2005) Epidemiology of male breast cancer. Cancer Epidemiol Biomarkers Prev 14:20-26. doi: 10.1158/1055-9965.EPI-05-0414

2. Fentiman IS, Fourquet A, Hortobagyi GN (2006) Male breast cancer. Lancet 367:595-604. doi:10.1016/S0140-6736(06) 68226-3

3. Nahleh Z, Girnius S (2006) Male breast cancer: a gender issue. Nat Clin Pract Oncol 3:428-437. doi:10.1038/ncponc0564

4. Meijers-Heijboer H, van den Ouweland A, Klijn J et al (2002) Low-penetrance susceptibility to breast cancer due to CHEK2(*)1100delC in noncarriers of BRCA1 or BRCA2 mutations. Nat Genet 31:55-59. doi:10.1038/ng879

5. Vahteristo P, Bartkova J, Eerola $\mathrm{H}$ et al (2002) A CHEK2 genetic variant contributing to a substantial fraction of familial breast cancer. Am J Hum Genet 71:432-438. doi:10.1086/341943

6. Consortium CBCC-C (2004) CHEK2*1100delC and susceptibility to breast cancer: a collaborative analysis involving 10,860 breast cancer cases and 9,065 controls from 10 studies. Am J Hum Genet 74:1175-1182. doi:10.1086/421251

7. Choi DH, Cho DY, Lee MH et al (2008) The CHEK2 1100delC mutation is not present in Korean patients with breast cancer cases tested for BRCA1 and BRCA2 mutation. Breast Cancer Res Treat. doi:10.1007/5105490079878z

8. Dufault MR, Betz B, Wappenschmidt B et al (2004) Limited relevance of the CHEK2 gene in hereditary breast cancer. Int $\mathrm{J}$ Cancer 110:320-325. doi:10.1002/ijc.20073

9. Evans DG, Bulman M, Young K et al (2007) BRCA1/2 mutation analysis in male breast cancer families from North West England. Fam Cancer 7:113-117. doi:10.1007/s10689-007-9153-9

10. Falchetti M, Lupi R, Rizzolo P et al (2008) BRCA1/BRCA2 rearrangements and CHEK2 common mutations are infrequent in Italian male breast cancer cases. Breast Cancer Res Treat 110:161-167. doi:10.1007/s10549-007-9689-2
11. Friedrichsen DM, Malone KE, Doody DR, Daling JR, Ostrander EA (2004) Frequency of CHEK2 mutations in a population based, case-control study of breast cancer in young women. Breast Cancer Res 6:R629-R635. doi:10.1186/bcr933

12. Jekimovs CR, Chen X, Arnold J et al (2005) Low frequency of CHEK2 1100delC allele in Australian multiple-case breast cancer families: functional analysis in heterozygous individuals. $\mathrm{Br} \mathrm{J}$ Cancer 92:784-790. doi:10.1038/sj.bjc.6602381

13. Karhu R, Laurila E, Kallioniemi A, Syrjakoski K (2006) Large genomic BRCA2 rearrangements and male breast cancer. Cancer Detect Prev 30:530-534. doi:10.1016/j.cdp.2006.10.002

14. Neuhausen S, Dunning A, Steele L et al (2004) Role of CHEK2*1100delC in unselected series of non-BRCA1/2 male breast cancers. Int J Cancer 108:477-478. doi:10.1002/ijc.11385

15. Offit K, Pierce H, Kirchhoff $\mathrm{T}$ et al (2003) Frequency of CHEK2*1100delC in New York breast cancer cases and controls. BMC Med Genet 4:1. doi:10.1186/1471-2350-4-1

16. Ohayon T, Gal I, Baruch RG, Szabo C, Friedman E (2004) CHEK2*1100delC and male breast cancer risk in Israel. Int $\mathrm{J}$ Cancer 108:479-480. doi:10.1002/ijc.11603

17. Sodha N, Wilson C, Bullock SL, Phillimore H, Houlston RS, Eeles RA (2004) Analysis of familial male breast cancer for germline mutations in CHEK2. Cancer Lett 215:187-189. doi: 10.1016/j.canlet.2004.07.002

18. Syrjakoski K, Kuukasjarvi T, Auvinen A, Kallioniemi OP (2004) CHEK2 1100delC is not a risk factor for male breast cancer population. Int J Cancer 108:475-476. doi:10.1002/ijc.11384

19. Meijers-Heijboer H, Wijnen J, Vasen H et al (2003) The CHEK2 1100delC mutation identifies families with a hereditary breast and colorectal cancer phenotype. Am J Hum Genet 72:13081314. doi: $10.1086 / 375121$

20. Wasielewski M, Vasen H, Wijnen J et al (2008) CHEK2 1100delC is a susceptibility allele for HNPCC-related colorectal cancer. Clin Cancer Res 14:4989-4994. doi:10.1158/1078-0432. CCR-08-0389

21. Meijer-van Gelder ME, Look MP, Bolt-de Vries J, Peters HA, Klijn JG, Foekens JA (2001) Clinical relevance of biologic factors in male breast cancer. Breast Cancer Res Treat 68:249-260. doi:10.1023/A:1012221921416

22. Easton DF, Pooley KA, Dunning AM et al (2007) Genome-wide association study identifies novel breast cancer susceptibility loci. Nature 447:1087-1093. doi:10.1038/nature05887

23. James JJ, Evans AJ, Pinder SE et al (2003) Bone metastases from breast carcinoma: histopathological-radiological correlations and prognostic features. Br J Cancer 89:660-665. doi:10.1038/sj.bjc. 6601198

24. Smid M, Wang Y, Klijn JG et al (2006) Genes associated with breast cancer metastatic to bone. J Clin Oncol 24:2261-2267. doi: 10.1200/JCO.2005.03.8802

25. Kilpivaara O, Laiho P, Aaltonen LA, Nevanlinna H (2003) CHEK2 1100delC and colorectal cancer. J Med Genet 40:e110. doi:10.1136/jmg.40.10.e110 